Article

\title{
Structural, Magnetic and Optical Properties of Gd and Co Co-Doped $\mathrm{YFeO}_{3}$ Nanopowders
}

\author{
Meng Wang $1, *,+\left(\mathbb{D}\right.$ and Ting Wang ${ }^{2,+}+\mathbb{C}$ \\ 1 School of Mechanical and Electrical Engineering, Shenzhen Polytechnic, Shenzhen 518055, China \\ 2 Shenzhen Key Laboratory of Advanced Materials, Department of Materials Science and Engineering, \\ Shenzhen Graduate School, Harbin Institute of Technology, Shenzhen 518055, China \\ * Correspondence: wangmeng04@szpt.edu.cn; Tel.: +86-755-26731137 \\ + These authors contributed equally to this work.
}

Received: 26 June 2019; Accepted: 23 July 2019; Published: 30 July 2019

\begin{abstract}
YFeO}_{3}, \mathrm{YFe}_{0.95} \mathrm{Co}_{0.05} \mathrm{O}_{3}, \mathrm{Y}_{0.95} \mathrm{Gd}_{0.05} \mathrm{FeO}_{3}$ and $\mathrm{Y}_{1-\mathrm{x}} \mathrm{Gd}_{\mathrm{x}} \mathrm{Fe}_{0.95} \mathrm{Co}_{0.05} \mathrm{O}_{3}(\mathrm{x}=$ 0.0, 0.05, 0.10, 0.15 and 0.20 ) nanopowders were successfully fabricated via a low-temperature solid-state reaction technique. Results obtained using X-ray diffraction (XRD), scanning electron microscopy (SEM), and Raman spectra indicate that $\mathrm{YFeO}_{3}$ nanopowders with $\mathrm{Gd}^{3+}$ and $\mathrm{Co}^{3+}$ ions co-doping at $\mathrm{Y}$ and Fe-sites were fabricated at $800{ }^{\circ} \mathrm{C}$ in sizes below $50 \mathrm{~nm}$, and a distorted structure was obtained. Magnetic hysteresis loop analyses illustrate that ferromagnetic behavior of $\mathrm{YFeO}_{3}$ nanopowders can be enhanced with the addition of $\mathrm{Gd}$ and $\mathrm{Co}$. Whereas the maximum and remnant magnetization of the powders were found to be about 5.24 and $2.6 \mathrm{emu} / \mathrm{g}$, respectively, the optical band gap was around $2.4 \mathrm{eV}$, proving that co-doped $\mathrm{YFeO}_{3}$ nanopowders have a strong capability to absorb visible light. Because both magnetic and optical properties of these materials are greatly improved with the addition of $\mathrm{Gd}$ and $\mathrm{Co}$, one can expect the scope of their potential application in the magnetic and optical fields to increase.
\end{abstract}

Keywords: multiferroics; low-temperature solid-state reaction; optical properties; magnetic properties; co-doping

\section{Introduction}

As one of the cutting edge multiferroic materials, $\mathrm{AFeO}_{3}(\mathrm{~A}=\mathrm{La}, \mathrm{Y}$ and $\mathrm{Sc})$ materials have been the focus of industry research because of their couple orderings of ferroelectricity and anti-ferromagnetism. As a result, they have great potential application in data storage, information exchange, and 5G mobile phone systems [1]. $\mathrm{YFeO}_{3}$ is one of the most promising applications of rare earth $\mathrm{AFeO}_{3}$ materials [2]. $\mathrm{YFeO}_{3}$ has been reported to feature molecular ferroelectricity at low temperatures (10-40 K), good dielectric and magnetic properties [3-6], and is also becoming one of the most widely investigated multiferroic materials. Moreover, with a narrow optical gap (1.9-2.6 eV), its potential application as an optical material, especially decomposing organics should be considered for further study [7]. However, pristine $\mathrm{YFeO}_{3}$ is not easy to prepare as evident by problems such as the introduction of secondary phases and the hopping of charge between $\mathrm{Fe}^{2+}$ and $\mathrm{Fe}^{3+}$ [8-10], while its low magnetism characteristics [11] are possibly its main shortcoming. Studies show that an effective and efficient way [11-13] to overcome these problems, is by means of doping. Some scientists substituted Y by divalent and trivalent ions [14,15] and Fe by trivalent and high-valence ions [16]. While the use of Gd doping is rarely reported, one study showed that with Gd doping on the Y site, significant enhancement of magnetization was achieved. In addition, use of other-element doping on the $Y$ site has the potential for improvement of the material's optical properties [15]. For Fe-site ion doping, the main improvement focus was the reduction of leakage current and the enhancement of magnetic 
properties. It is known [17] that $\mathrm{Y}(\mathrm{Fe}, \mathrm{Cr}) \mathrm{O}_{3}$ showed evidence of ferromagnetic property. Ma et al. [18] synthesized $\mathrm{Mn}$ doped $\mathrm{YFeO}_{3}$ by using a standard solid-state reaction method. Their findings showed that the leakage current was reduced so that ferroelectric properties are realized at room temperature.

Co doping may enhance the magnetic properties of $\mathrm{RFeO}_{3}$ material because it is magnetically active. While there is no report of co-doping of $\mathrm{Co}$ and $\mathrm{Gd}$, the purpose of this paper is the study of co-doping of $\mathrm{Co}$ and $\mathrm{Gd}$ on $\mathrm{YFeO}_{3}$ with a particular emphasis on the microstructural, optical, and magnetic properties of the doped $\mathrm{YFeO}_{3}$ nanopowders.

\section{Experimental Procedures}

$\mathrm{YFeO}_{3}$ (abbreviated as YFO), $\mathrm{YFe}_{0.95} \mathrm{Co}_{0.05} \mathrm{O}_{3}(\mathrm{Co} 5), \mathrm{Y}_{0.95} \mathrm{Gd}_{0.05} \mathrm{FeO}_{3}(\mathrm{Gd} 5), \mathrm{Y}_{0.95} \mathrm{Gd}_{0.05} \mathrm{Fe}_{0.95} \mathrm{Co}_{0.05} \mathrm{O}_{3}$ (Gd5Co5), $\mathrm{Y}_{0.9} \mathrm{Gd}_{0.1} \mathrm{Fe}_{0.95} \mathrm{Co}_{0.05} \mathrm{O}_{3}(\mathrm{Gd} 10 \mathrm{Co} 5), \mathrm{Y}_{0.85} \mathrm{Gd}_{0.15} \mathrm{Fe}_{0.95} \mathrm{Co}_{0.05} \mathrm{O}_{3}\left(\mathrm{Gd} 15 \mathrm{Co}\right.$ ), and $\mathrm{Y}_{0.8} \mathrm{Gd}_{0.2} \mathrm{Fe}_{0.95}$ $\mathrm{Co}_{0.05} \mathrm{O}_{3}(\mathrm{Gd} 20 \mathrm{Co5})$ nanoparticles were synthesized using a low-temperature solid-state reaction technique as described in Ref. [19]. The raw reagents include $\mathrm{Fe}\left(\mathrm{NO}_{3}\right)_{3} \cdot 9 \mathrm{H}_{2} \mathrm{O}, \mathrm{Y}\left(\mathrm{NO}_{3}\right)_{3} \cdot 6 \mathrm{H}_{2} \mathrm{O}$, $\mathrm{Co}\left(\mathrm{NO}_{3}\right)_{2} \cdot 6 \mathrm{H}_{2} \mathrm{O}, \mathrm{Gd}\left(\mathrm{NO}_{3}\right)_{3} \cdot 6 \mathrm{H}_{2} \mathrm{O}$, and citric acid. Initially, $\mathrm{Fe}\left(\mathrm{NO}_{3}\right)_{3} \cdot 9 \mathrm{H}_{2} \mathrm{O}, \mathrm{Y}\left(\mathrm{NO}_{3}\right)_{3} \cdot 6 \mathrm{H}_{2} \mathrm{O}$ and citric acid were weighed stoichiometrically and ground in an agate mortar for half an hour, respectively. The respective powders were then mixed and ground again in an agate mortar for half an hour. A light brown viscous substance was formed during the grinding process, implying that the complex was formed. The viscous substance was heated at $120^{\circ} \mathrm{C}$ for $2 \mathrm{~h}$ to remove free water and then a powdery composite was harvested, serving as the precursor powders. The powders were ground and subsequently calcined for $1 \mathrm{~h}$ in air at $800{ }^{\circ} \mathrm{C}$ to provide the nanoparticles. The crystal structures and morphology of the calcined particles were examined using XRD (D/max-RB, Rigaku, Tokyo, Japan) and SEM (S-4700, Hitachi, Tokyo, Japan). Raman spectra (InVia Reflex, Renishaw, London, UK spectrometer) were measured at room temperature with a range of $100 \mathrm{~cm}^{-1}$ to $1500 \mathrm{~cm}^{-1}$. Magnetic hysteresis loops were measured using PPMS (Physical Property Measurement System, DynaCool-9T, Quantum Design, Leatherhead, Surrey, UK). Optical absorbance properties of the experimental nanopowders were examined using a UV-Visible spectrophotometer (Shimadzu, UV-2600, Kyoto, Japan).

\section{Results and Discussions}

Figure 1a presents the $X R D$ patterns of the tested $(0 \leq x \leq 0.2)$ samples calcined at $800^{\circ} \mathrm{C}$. The pattern for the pristine $\mathrm{YFeO}_{3}$ nanopowders suggests the presence of the obvious orthorhombic $\mathrm{YFeO}_{3}$ pattern and that no minor impurity peaks were present. This outcome shows that the synthesis reaction for the orthorhombic structure was completed and the purity was high. The doped nanopowders indicate the same characteristic shape as that of the pristine $\mathrm{YFeO}_{3}$ patterns with a slight shift in the peak position and phase. For Gd5, some peaks for the hexagonal $\mathrm{YFeO}_{3}$ structure emerged. For $\mathrm{Co} 5$, peaks for $\mathrm{Y}_{2} \mathrm{O}_{3}$ appeared, showing that some minor impurity was introduced. This is a normal situation involving the case where instability of $\mathrm{YFeO}_{3}$ exists and which is due to the radius difference. However, this effect totally disappears for the Co-Gd co-doped sample. Figure $1 \mathrm{~b}$ shows the $\mathrm{YFeO}_{3}$ peaks at $2 \theta \sim 33^{\circ}$, shifting toward a higher $2 \theta$ angle with substitution of $\mathrm{Co}$ into $\mathrm{YFeO}_{3}$. The figure also shows a shift towards a lower $2 \theta$ angle with further substitution of $\mathrm{Gd}$ into $\mathrm{YFeO}_{3}$, and while keeping almost the same position of $\mathrm{Gd}$ and Co-doped samples due to $\mathrm{Gd}^{3+}\left(\mathrm{Gd}^{3+} 0.938 \AA\right)$ possessed a larger ionic radii compared with $\mathrm{Y}^{3+}\left(\mathrm{Y}^{3+} 0.9 \AA\right)$, and $\mathrm{Co}^{3+}\left(\mathrm{Co}^{3+} 0.61 \AA\right)$ possessed a smaller one compared with $\mathrm{Fe}^{3+}$ $\left(\mathrm{Fe}^{3+} 0.645 \AA\right)[15,20]$. Thus, it is evident that $\mathrm{Gd}^{3+}$ and $\mathrm{Co}^{3+}$ replaced the $\mathrm{Y}^{3+}$ and $\mathrm{Fe}^{3+}$ ions in $\mathrm{YFeO}_{3}$, respectively. The XRD pattern shows the highest peak for the Co-doped particles and its $2 \theta$ angle location is nearly identical to that of pure YFO. The stress introduced by the change in radius was reduced so that impurities disappeared.

Table 1 shows the lattice parameters with different Co and Gd concentrations. All these values increased with increase in Gd content and decreased with Co addition. This behavior demonstrates that the replacement of $\mathrm{Y}^{3+}$ with $\mathrm{Gd}^{3+}$ results in the increase of the lattice volume of $\mathrm{YFeO}_{3}\left(\mathrm{r}_{\mathrm{Gd}}{ }^{3+}>\mathrm{rY}^{3+}\right)$, whereas the replacement of $\mathrm{Fe}^{3+}$ with $\mathrm{Co}^{3+}$ results in the decrease of $\mathrm{YFeO}_{3}$ volume $\left(\mathrm{r}_{\mathrm{Co}}{ }^{3+}<\mathrm{r}_{\mathrm{Fe}}{ }^{3+}\right)$. 
The continuous evolution of lattice parameters with increasing Gd and Co concentrations also shows the presence of a successful substitution of $\mathrm{Y}^{3+}$ and $\mathrm{Fe}^{3+}$ ions by $\mathrm{Gd}^{3+}$ and $\mathrm{Co}^{3+}$ ions.
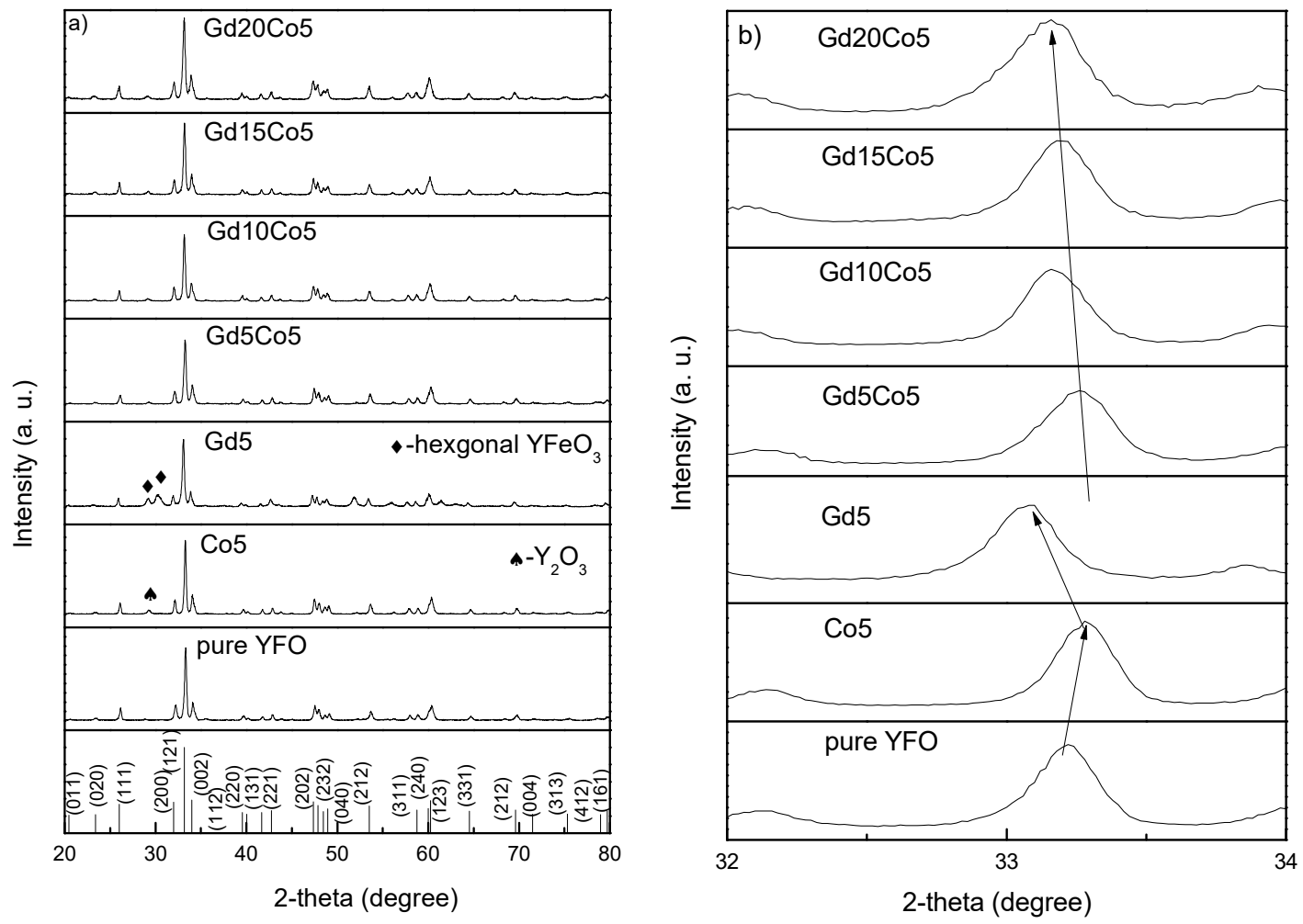

Figure 1. (a) XRD patterns of as-prepared nanoparticles calcined at $800{ }^{\circ} \mathrm{C}$; (b) the magnified patterns of peaks at $2 \theta \sim 32^{\circ}$.

Table 1. Lattice parameters and volume of the samples.

\begin{tabular}{ccccc}
\hline Sample & $\mathbf{a}(\AA)$ & $\mathbf{b}(\AA)$ & $\mathbf{c}(\AA)$ & Volume $\left.^{(\AA} \mathbf{\AA}^{3}\right)$ \\
\hline Pure YFO & 5.58079 & 5.27096 & 7.58866 & 223.23 \\
Co5 & 5.57756 & 5.26958 & 7.58258 & 222.86 \\
Gd5 & 5.58195 & 5.27209 & 7.5924 & 223.43 \\
Gd5Co5 & 5.58018 & 5.27106 & 7.58943 & 223.23 \\
Gd10Co5 & 5.58255 & 5.27279 & 7.59356 & 223.52 \\
Gd15Co5 & 5.58303 & 5.27411 & 7.59364 & 223.60 \\
Gd20Co5 & 5.58523 & 5.27791 & 7.59615 & 223.92 \\
\hline
\end{tabular}

SEM images of $\mathrm{YFeO}_{3}$ nanopowders are shown in Figure 2. These demonstrate that the particle sizes of the test nanopowders were homogeneous with some minor agglomeration. The particle sizes of the test samples of YFO, Co5, Gd5, Co5Gd5, Co5Gd10, Co5Gd15 and Co5Gd20 were approximately 150, 120, 95, 80, 75, 45 and $40 \mathrm{~nm}$, respectively. From the results obtained, it is apparent that the Co and Gd substitution decreased the grain size, while particle size decreased significantly with Co and Gd co-doping. As is well known, whenever the diffusion rate is low, rare earth ions can inhibit grain growth of $\mathrm{RFeO}_{3}$ [11]. In addition, $\mathrm{Gd}^{3+}$ ions (radius of $0.983 \AA$ ) are larger than $\mathrm{Y}^{3+}$ ions (radius of $0.9 \AA$ ). The mismatch of ion sizes introduces defects in the lattice, leading to particle refinement. In addition, $\mathrm{Co}^{3+}$ can suppress hopping of $\mathrm{Fe}^{2+}$ and $\mathrm{Fe}^{3+}$, depriving the oxygen vacancy and subsequently preventing growth of the grains [21]. Some agglomeration of particles appears in Co and Gd co-doping samples, and may be attributed to the large surface area to volume ratio of the nanoparticles. The latter is to be expected whenever the low-temperature solid-state reaction method 
is used. Similar effects of grain refinement induced by rare earth and magnetic element co-doping has been reported in other references $[14,17,21,22]$.
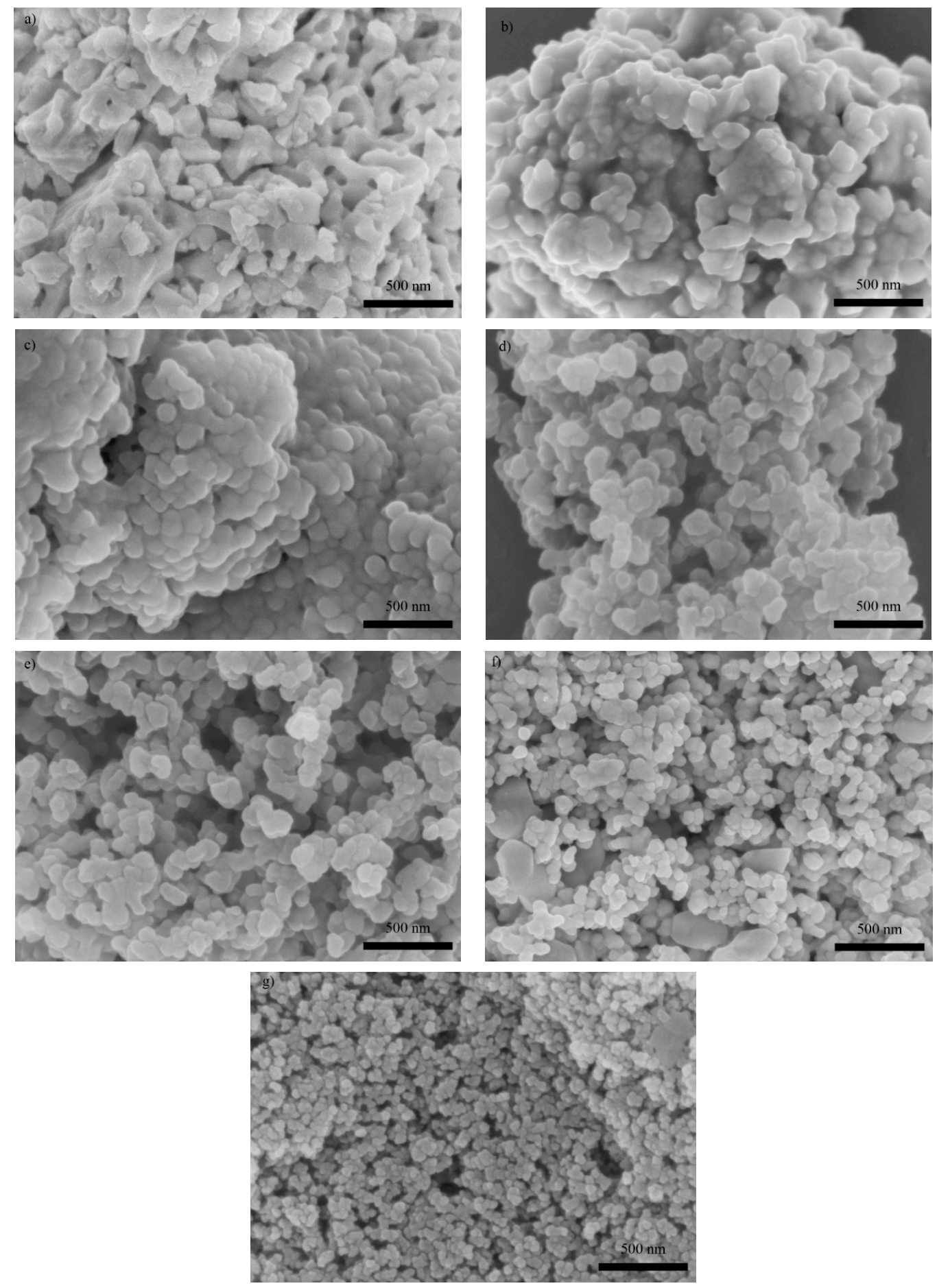

Figure 2. SEM micrographs of as-prepared nanoparticles: (a) YFO; (b) Co5; (c) Gd5; (d) Gd5Co5; (e) Gd10Co5; (f) Gd15Co5; (g) Gd20Co5.

Figure 3 shows the Raman patterns obtained from the $\mathrm{YFeO}_{3}$ powders. As is well known, for the case involving the Pnma structure of $\mathrm{YFeO}_{3}$, only modes of $\mathrm{A}_{1 \mathrm{~g}}, \mathrm{~B}_{1 \mathrm{~g}}, \mathrm{~B}_{2 \mathrm{~g}}$, and $\mathrm{B}_{3 \mathrm{~g}}$ are active. Furthermore, one can say with a high degree of certainty that the first and second $\mathrm{A}_{1 \mathrm{~g}}$ modes are associated with $\mathrm{Y}-\mathrm{O}$ bonds, and the $\mathrm{A}_{1 \mathrm{~g}}$ and $\mathrm{B}_{\mathrm{g}}$ modes are related to $\mathrm{Fe}-\mathrm{O}$ bonds at higher 
frequencies [23]. The $221 \mathrm{~cm}^{-1} \mathrm{~A}_{1 \mathrm{~g}}$ mode is represented as an $\mathrm{FeO}_{6}$ octahedral structure $[9,10,24]$. The vibrating modes of Co5 were similar to those of pure YFO, while the intensity was reduced slightly and the peak at $610 \mathrm{~cm}^{-1}$ increased as expected owing to the minor change of $\mathrm{Fe}-\mathrm{O}$ bonds resulting from the doping of the Co element. For the case involving substitution of $\mathrm{Gd}^{3+}$ for $\mathrm{Y}^{3+}$, the parameters of lattice (grain size) increased, leading to a shift in the Raman bands to a lower wave-number. Raman bands were found to broaden with increase of $\mathrm{Gd}^{3+}$ and $\mathrm{Co}^{3+}$ (in $\mathrm{YFeO}_{3}$ ) because of the disorder introduced by two different cations. The Gd-O and $\mathrm{Y}-\mathrm{O}$ bonds, with their inherent different strengths, can influence their vibration frequencies. In general, one can state that these results are consistent with the XRD patterns. Thus, it can be concluded that Co and Gd co-doping has a substantial effect on the modification of the $\mathrm{YFeO}_{3}$ structure.
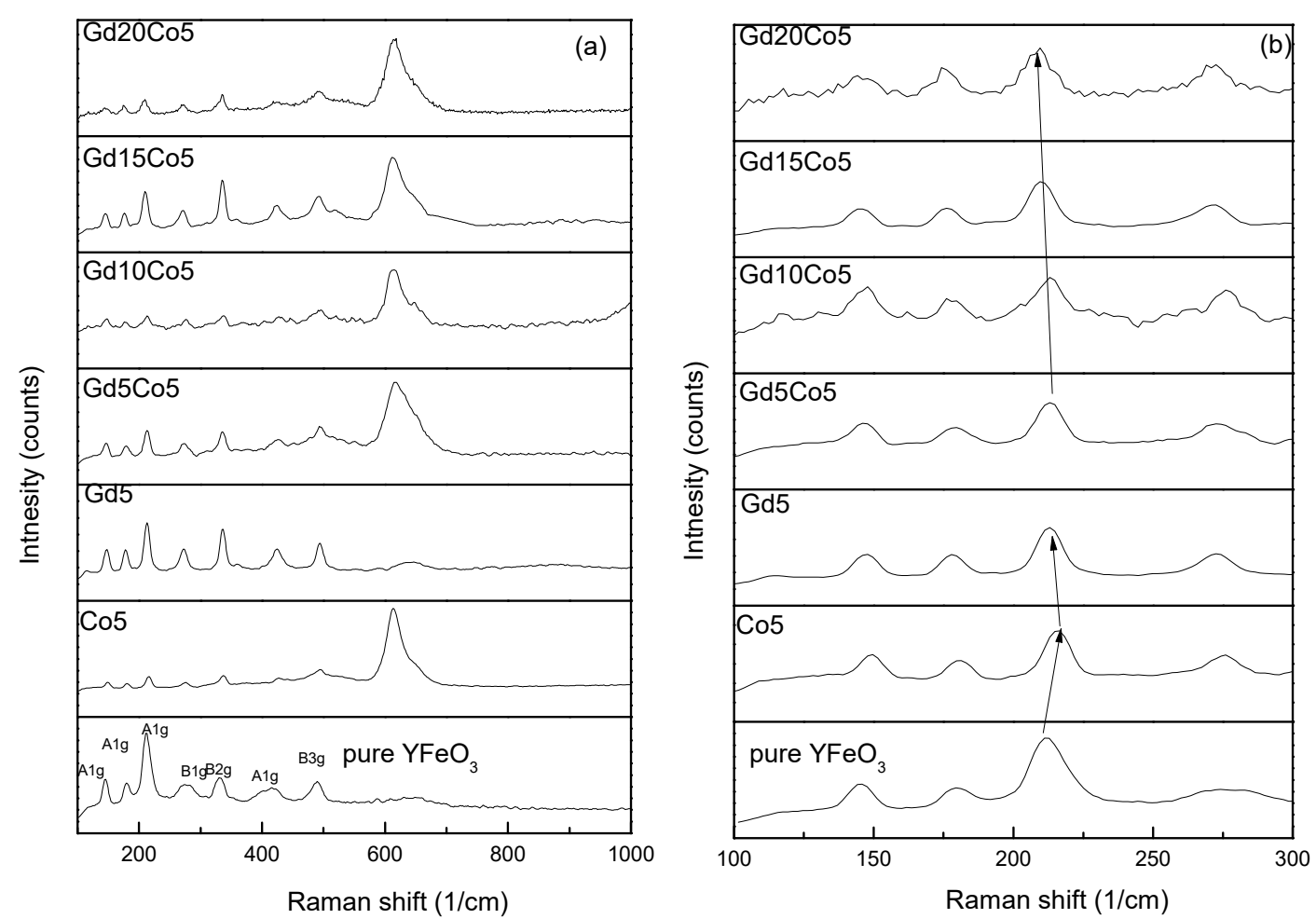

Figure 3. (a) Raman spectra of as-prepared nanoparticles. (b) The magnified patterns of $221 \mathrm{~cm}^{-1}$.

Figure 4 shows the magnetic properties of the nanopowders at room temperature. Values of maximum magnetization $\left(M_{m}\right)$, remnant magnetization $\left(M_{r}\right)$, and the coercive field $\left(H_{\mathcal{C}}\right)$ of the test samples are listed in Table 2. As is commonly known, $\mathrm{YFeO}_{3}$ is antiferromagnetic and features weak magnetic properties. In the case of pristine $\mathrm{YFeO}_{3}$, the hysteresis loop is typical weak magnetization in antiferromagnetic type. The magnetization parameters for the pristine $\mathrm{YFeO}_{3}$ sample $M_{m}, M_{r}$, and $H_{c}$ had magnitudes of $3.50 \mathrm{emu} / \mathrm{g}, 0.89 \mathrm{emu} / \mathrm{g}$, and 161 Oe. For the case involving the doped samples, a large open region was seen at the center of the hysteresis loops suggesting ferromagnetic behavior. Even when exposed to a $60 \mathrm{kOe}$ outer magnetic field, the loops were not saturated. For Co5, $M_{m}$, $M_{r}$ were slightly improved and $H_{c}$ was reduced. Their corresponding values were about $4.56 \mathrm{emu} / \mathrm{g}$, $0.95 \mathrm{emu} / \mathrm{g}$ and $120 \mathrm{Oe}$, respectively. For the case of co-doping of Co and Gd, the net magnetization decreased slightly at first, and then began to increase, reaching a high value of $5.24 \mathrm{emu} / \mathrm{g}$ for the Co5Gd20 particles. These values are summarized in Table 2. The value of $M_{r}$ reached a maximum $\left(M_{r}=1.66 \mathrm{emu} / \mathrm{g}\right)$ for the Co5Gd5 nanoparticles. The reasons for observed improvement of the magnetization may be summarized as follows:

(1) The effect of nanoparticles. Uncompensated surface spins of $\mathrm{Fe}^{3+}$ ions are created when particle size is small. This situation leads to a strong magnetic enhancement $[25,26]$. 
(2) The distorted structure is affected by the doping effect. $\mathrm{A} \mathrm{FeO}_{6}$ octahedron structure consists of one $\mathrm{Fe}^{3+}$ ion and six $\mathrm{O}^{2-}$ ions, while each $\mathrm{Fe}^{3+}$ magnetic moment is not precisely parallel to the neighboring ones, forming a small angle $[25,26]$, which causes weak ferromagnetism in the antiferromagnetic $\mathrm{YFeO}_{3}$. Substituting an $\mathrm{Fe}^{3+}$ ion with a larger radius $\mathrm{Co}^{3+}$ ion will reduce the canted angle of the $\mathrm{FeO}_{6}$ octahedra and release the distortion, and combined with a refined powder size, a higher magnetization is achieved. [27].

(3) The $\mathrm{Gd}^{3+}$ ion with a large magnetic moment $\left(\mu_{\text {eff }}=8.0 \mu_{\mathrm{B}}\right)$ is magnetically active. When $\mathrm{Y}^{3+}$ is replaced by $\mathrm{Gd}^{3+}$, Y-O- $\mathrm{Gd}$ chains instead of $\mathrm{Gd}-\mathrm{O}-\mathrm{Gd}$ chains are formed, further improving the magnetization of the $\mathrm{Co}$ and $\mathrm{Gd}$ co-doped nanopowders [15].

In summary, the three reasons noted above serve to bring about the enhancement of magnetization. Others who conducted similar research made similar findings. Khalifa et al. [16] reported that $M_{m}$ and $M_{r}$ were about $0.8 \mathrm{emu} / \mathrm{g}$ and $0.1 \mathrm{emu} / \mathrm{g}$ for Ti-doped $\mathrm{YFeO}_{3}$ nanoparticles prepared using an improved sol-gel technique. Shi et al. [17] synthesized $\mathrm{YFe}_{0.5} \mathrm{Cr}_{0.5} \mathrm{O}_{3}$ nanoparticles by the sol-gel method, and showed that $M_{m}$ and $M_{r}$ were approximately 2.0 and $0.5 \mathrm{emu} / \mathrm{g}$, respectively. As reported by Shi, the maximum $M_{m}$ and $M_{r}$ values for $\mathrm{Y}_{0.95} \mathrm{Ho}_{0.05} \mathrm{Fe}_{0.5} \mathrm{Cr}_{0.5} \mathrm{O}_{3}$ nanoparticles prepared using a low-temperature citric acid assisted sol-gel technology were about 4.5 and $1.2 \mathrm{emu} / \mathrm{g}$, respectively [17]. Yuan et al. [15] synthesized $\mathrm{Y}_{0.9} \mathrm{Gd}_{0.1} \mathrm{FeO}_{3}$ using a solid-state reaction method, and obtained values of $M_{m}, M_{r}$, and $H_{c}$ of $2.5 \mathrm{emu} / \mathrm{g}, 1.0 \mathrm{emu} / \mathrm{g}$ and 30,000 Oe, respectively. Still, it is worth noting that the property values in the present study are comparable with, or better than the results reported by others.
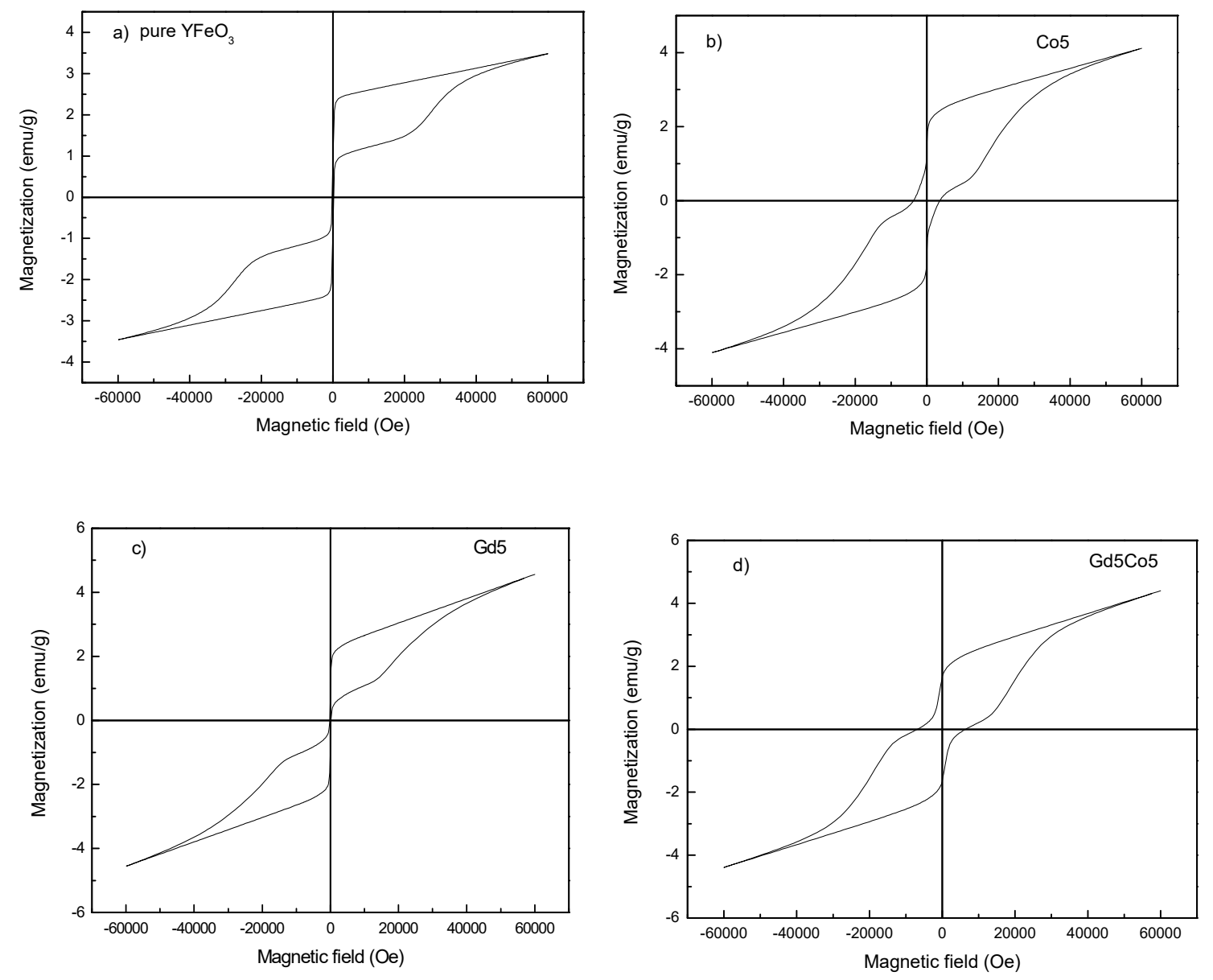

Figure 4. Cont. 

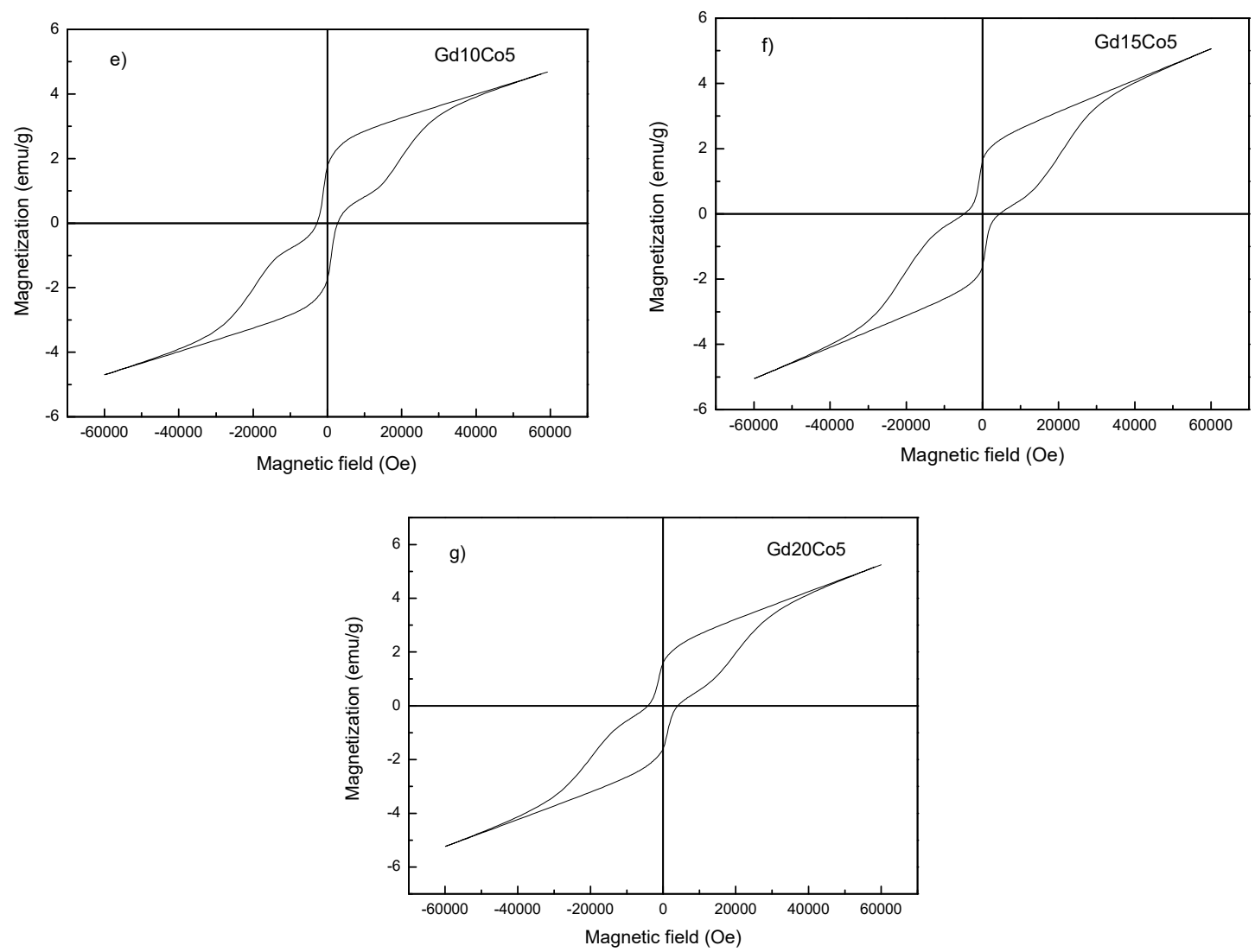

Figure 4. Magnetic hysteresis loops of as-prepared nanoparticles: (a) YFO; (b) Co5; (c) Gd5; (d) Gd5Co5; (e) Gd10Co5; (f) Gd15Co5; (g) Gd20Co5.

Table 2. List of the magnetic and optical parameters for $\mathrm{YFeO}_{3}$ powders.

\begin{tabular}{ccccc}
\hline Sample & $\boldsymbol{M}_{\boldsymbol{m}} \mathbf{( e m u / g )}$ & $\boldsymbol{M}_{\boldsymbol{r}}(\mathbf{e m u} / \mathbf{g})$ & $\boldsymbol{H}_{\boldsymbol{c}} \mathbf{( k O e )}$ & Photon Energy (eV) \\
\hline Pure YFO & 3.49 & 0.88 & 160 & 2.42 \\
Co5 & 4.10 & 1.47 & 3700 & 2.34 \\
Gd5 & 4.56 & 0.84 & 170 & 2.33 \\
Gd5Co5 & 4.40 & 1.66 & 6800 & 2.32 \\
Gd10Co5 & 4.68 & 1.76 & 2800 & 2.32 \\
Gd15Co5 & 5.05 & 1.62 & 4800 & 2.29 \\
Gd20Co5 & 5.24 & 1.60 & 4200 & 2.24 \\
\hline
\end{tabular}

$\mathrm{YFeO}_{3}$ possesses a narrow optical band gap (1.6-2.4 eV) and has been used in light-electric energy conversion applications. From the UV-visible absorption spectra (Figure 5), the optical energy band gap $\left(E_{g}\right)$ of the seven test samples can be calculated using a Tauc function expressed in Equation (1) [28]:

$$
(\alpha h v)^{n}=A\left(h v-E_{g}\right)
$$

The $E_{g}$ values shown in Figure 5 illustrate strong visible light absorption, indicating their promising decomposition application (See Table 2). YFO has the maximum $E_{g}$ value $(2.42 \mathrm{eV})$. It is decreased to $2.15 \mathrm{eV}$ for Gd20Co5 nanoparticles. Clearly, the energy band gap becomes smaller with refined particle size of the $\mathrm{YFeO}_{3}$ powders. Thus, the reduction of the energy gap with co-doping is ascribed to the smaller particle size and lattice distortion reduction generated by the addition of Co and Gd. Further, according to Reference [23], reduced particle size leads to a narrow energy gap. Nonuniform microstrains caused by lattice distortions can impact energy levels, affecting the energy band gap [28,29]. $\mathrm{YFeO}_{3}$ possesses the band gap of $2 \mathrm{p} \mathrm{O}$, and $4 \mathrm{~d} \mathrm{Y}$ atoms. All these states are partially filled [28]. 
The Gd atom is with the $4 \mathrm{f}$ state which is also not fully filled orbits. Thus $\mathrm{f}-\mathrm{d}$ hybridization of the $4 \mathrm{~d} \mathrm{Y}$ and $3 \mathrm{~d} F$ Fe atoms causes light absorption. In addition, the same $\mathrm{d}$ states of Fe and Co overlap with the $2 p$ states $\mathrm{O}$ atom, causing a narrow energy gap $[15,30]$. Moreover, $\mathrm{Gd}^{3+}$ and $\mathrm{Co}^{3+}$ ions partially substituting $\mathrm{Y}^{3+}$ and $\mathrm{Fe}^{3+}$ ions refine the as-synthesized nanoparticles size and increase chemical pressure, thereby resulting in a smaller value of $E_{g}$ [30]. Zhang et al. [28] obtained $E_{g}$ values of 1.94, 2.43 and $2.30 \mathrm{eV}$, respectively, for the hexagonal, orthorhombic, and $\mathrm{YFeO}_{3}$ containing a mixture of the two phases. Shen et al. [31] reported that the $E_{g}$ value obtained from a first-principles calculation for $\mathrm{YFeO}_{3}$ ceramics was $2.58 \mathrm{eV}$. Wu et al. [23] prepared $\mathrm{YFeO}_{3}$ in which, hexagonal and orthorhombic phases co-existed; this material had a band gap of $2.41 \mathrm{eV}$. For $\mathrm{YFeO}_{3}$ ceramics prepared by the conventional solid-state method, the energy band gap was found to be $2.58 \mathrm{eV}$ [7]. Liu et al. [32] measured the optical properties of hexagonal- $\mathrm{YFeO}_{3} / \alpha-\mathrm{Fe}_{2} \mathrm{O}_{3}$ heterojunction composite nanowire and obtained $E_{g}$ values of approximately $2.15 \mathrm{eV}$. Once again, it is worth noting that our $E_{g}$ values compare favorably with these results. Therefore, one can reasonably conclude that the $\mathrm{YFeO}_{3}$ nanopowders used in this study can be used in the decomposition of organic compounds.
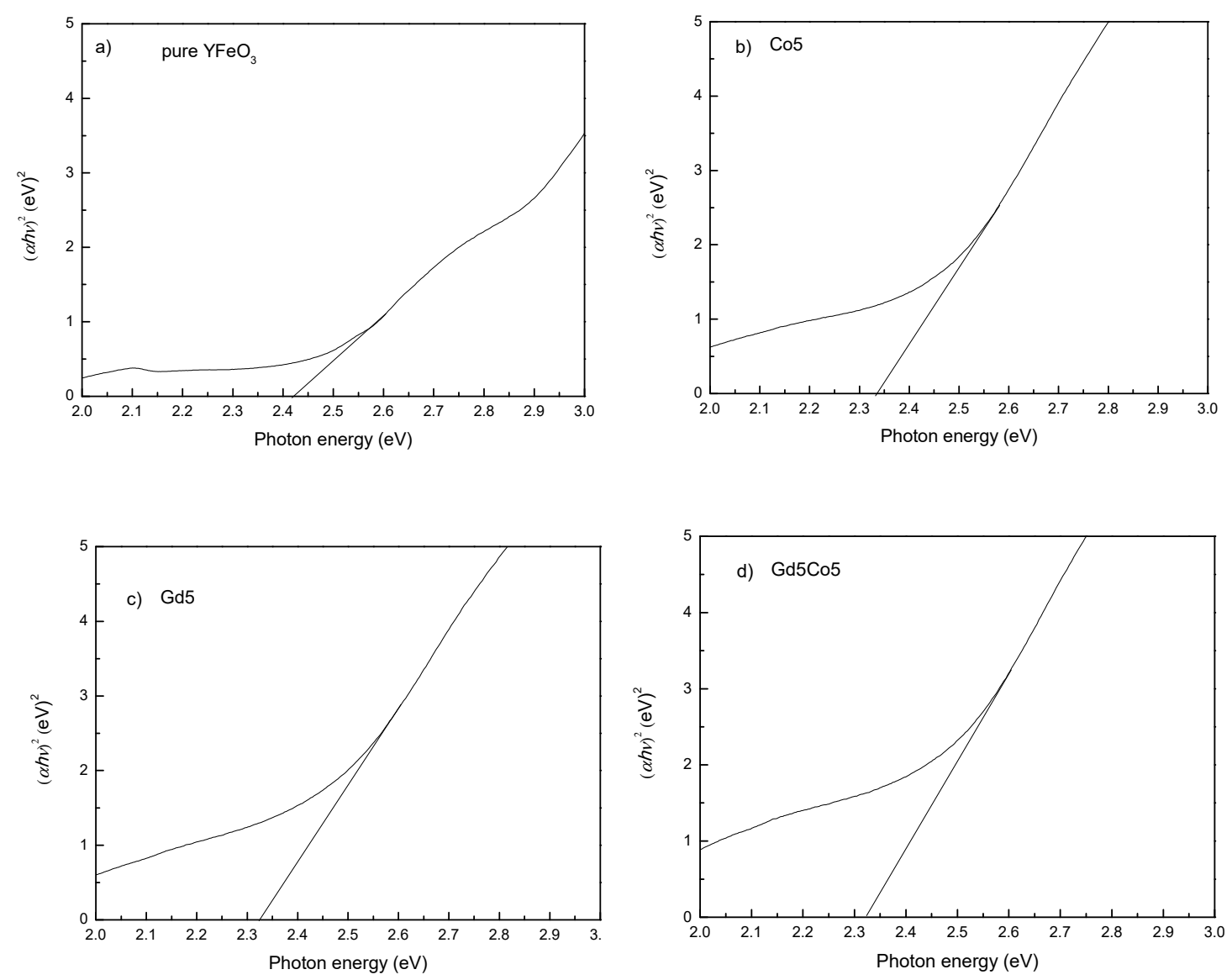

Figure 5. Cont. 

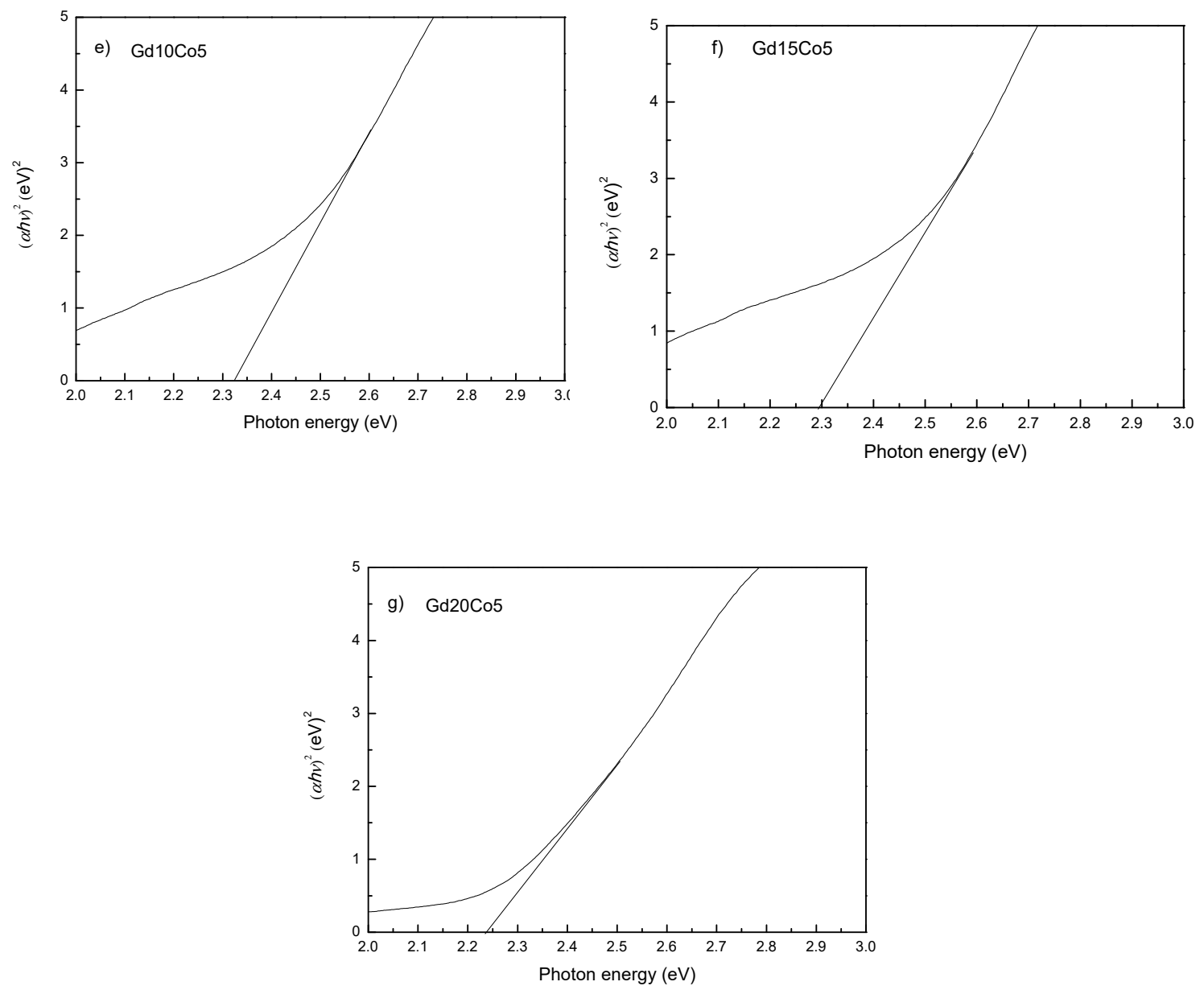

Figure 5. $(\alpha h v)^{2}$ as a function of photon energy for as-prepared nanoparticles: (a) YFO; (b) Co5; (c) Gd5; (d) Gd5Co5; (e) Gd10Co5; (f) Gd15Co5; (g) Gd20Co5.

\section{Conclusions}

$\mathrm{Co}$ and $\mathrm{Gd}$ co-doped $\mathrm{YFeO}_{3}$ nanopowders were fabricated using a low-temperature solid-state reaction method. Data obtained using XRD and Raman analyses show that, with Gd and Co substitution, $\mathrm{YFeO}_{3}$ nanoparticles exhibit a distortion refined structure. The particle size for pristine $\mathrm{YFeO}_{3}$ nanoparticles is about 100-200 nm, and those for Co5, Gd5, Co5Gd5, Co5Gd10, Co5Gd15 and Co5Gd20 are approximately 120, 95, 80, 75, 45 and $40 \mathrm{~nm}$, respectively. The maximum magnetization and remnant magnetization for the co-doped $\mathrm{YFeO}_{3}$ powders are about 5.49 and $2.20 \mathrm{emu} / \mathrm{g}$, respectively, when exposed to a magnetic field of $60 \mathrm{kOe}$. The energy band gap of $\mathrm{YFeO}_{3}$ nanopowders was reduced from 2.41 to 2.23 using the co-doping method, thereby indicating their potential in decomposition applications. Because the co-doping method used in the study was found to be easy to control for fabricating the $\mathrm{YFeO}_{3}$ nanopowder samples, it is proposed that the method be adopted for use in the applied magnetic and optical fields.

Author Contributions: M.W. and T.W. conceived and designed the experiments; M.W. performed the experiments; M.W. and T.W. analyzed the data; M.W. wrote the paper.

Funding: This research was funded by the Research Funding of Shenzhen Polytechnic (6019310005K).

Conflicts of Interest: The authors declare no conflict of interest. 


\section{References}

1. Dho, J.; Blamire, M. Competing functionality in multiferroic $\mathrm{YMnO}_{3}$. Appl. Phys. Lett. 2005, 87, 2504. [CrossRef]

2. Wang, L.J.; Feng, S.M.; Zhu, J.L.; Yu, R.C.; Jin, C.Q.; Yu, W.; Wang, X.H.; Li, L.T. Ferroelectricity of multiferroic hexagonal $\mathrm{TmMnO}_{3}$ ceramics synthesized under high pressure. Appl. Phys. Lett. 2007, 91, 172502. [CrossRef]

3. Cherry, M.; Islam, M.S.; Catlow, C.R.A. Oxygen ion migration in perovskite-type oxides. J. Solid State Chem. 1995, 118, 125-132. [CrossRef]

4. Minh, N.Q. Ceramic fuel cells. J. Am. Ceram. Soc. 1993, 76, 563-588. [CrossRef]

5. Sharon, M.; Prasad, B.M. Preparation and photocharacterization of $\mathrm{YFeO}_{3}$ semiconductor. Electrochim. Acta 1985, 30, 331-334. [CrossRef]

6. Traversa, E.; Nunziante, P.; Sangaletti, L.; Allieri, B.; Depero, L.E.; Aono, H.; Sadaoka, Y. Synthesis and structural characterization of trimetallic perovskite-type rare-earth orthoferrites, $\mathrm{La}_{\mathrm{x}} \mathrm{Sm}_{1-\mathrm{x}} \mathrm{FeO}_{3}$. J. Am. Ceram. Soc. 2000, 83, 1087-1092. [CrossRef]

7. Butler, M.A.; Ginley, D.S.; Eibschutz, M. Photoelectrolysis with $\mathrm{YFeO}_{3}$ electrodes. J. Appl. Phys. 1977, 48, 3070-3072. [CrossRef]

8. Mathur, S.; Veith, M.; Rapalaviciute, R.; Shen, H.; Goya, G.F.; Filho, W.L.M.; Berquo, T.S. Molecule derived synthesis of nanocrystalline $\mathrm{YFeO}_{3}$ and investigations on its weak ferromagnetic behavior. Chem. Mater. 2004, 16, 1906-1913. [CrossRef]

9. Schmool, D.S.; Keller, N.; Guyot, M.; Krishnan, R.; Tessier, M. Magnetic and magneto-optic properties of orthoferrite thin films grown by pulsed-laser deposition. J. Appl. Phys. 1999, 86, 5712-5717. [CrossRef]

10. Shang, M.; Wang, C.; Chen, Y.; Sun, F.; Yuan, H. The multiferroic epitaxial thin film $\mathrm{YFeO}_{3}$. Mater. Lett. 2016, 175, 23-26. [CrossRef]

11. Akbashev, A.; Semisalova, A.; Perov, N.; Kaul, A. Weak ferromagnetism in hexagonal orthoferrites $\mathrm{RFeO}_{3}$ $(\mathrm{R}=\mathrm{Lu}, \mathrm{Er}-\mathrm{Tb})$. Appl. Phys. Lett. 2011, 99, 122502. [CrossRef]

12. Hemberger, J.; Schrettle, F.; Pimenov, A.; Lunkenheimer, P.; Ivanov, V.Y.; Mukhin, A.A.; Balbashov, A.M.; Loidl, A. Multiferroic phases of $\mathrm{Eu}_{1-\mathrm{x}} \mathrm{Y}_{\mathrm{x}} \mathrm{MnO}_{3}$. Phys. Rev. B Condens. Matter 2007, 75, 5118. [CrossRef]

13. Zhang, W.; Fang, C.; Yin, W.; Zeng, Y. One-step synthesis of yttrium orthoferrite nanocrystals via sol-gel auto-combustion and their structural and magnetic characteristics. Mater. Chem. Phys. 2013, 137, 877-883. [CrossRef]

14. Van Tac, D.; Mittova, V.; Mittova, I.Y. Influence of lanthanum content and annealing temperature on the size and magnetic properties of sol-gel derived $\mathrm{Y}_{1-x} \mathrm{La}_{x} \mathrm{FeO}_{3}$ nanocrystals. Inorg. Mater. 2011, 47, 521-526. [CrossRef]

15. Yuan, X.; Sun, Y.; Xu, M. Effect of Gd substitution on the structure and magnetic properties of $\mathrm{YFeO}_{3}$ ceramics. J. Solid State Chem. 2012, 196, 362-366. [CrossRef]

16. Khalifa, N.O.; Widatallah, H.M.; Gismelseed, A.M. Magnetic and Mössbauer studies of pure and Ti-doped $\mathrm{YFeO}_{3}$ nanocrystalline particles prepared by mechanical milling and subsequent sintering. Hyperfine Interact. 2016, 237, 1-11. [CrossRef]

17. Shi, L.R.; Xia, Z.C.; Huang, S.; Xiao, G.L.; Jin, Z.; Wei, M.; Chen, B.R.; Shang, C.; Cheng, H.; Ouyang, Z.W. The magnetization reversal and high temperature dielectric response in $\mathrm{Y}_{1-x} \mathrm{H}_{\mathrm{x}} \mathrm{Fe}_{0.5} \mathrm{Cr}_{0.5} \mathrm{O}_{3}$. Ceram. Int. 2016, 42, 10808-10812. [CrossRef]

18. Ma, Y.; Wu, Y.J.; Lin, Y.Q.; Chen, X.M. Microstructures and multiferroic properties of $\mathrm{YFe}_{1-\mathrm{x}} \mathrm{Mn}_{\mathrm{x}} \mathrm{O}_{3}$ ceramics prepared by spark plasma sintering. J. Mater. Sci. Mater. Electron. 2010, 21, 838-843. [CrossRef]

19. Wang, M.; Wang, T.; Song, S.; Tan, M. Structure-controllable synthesis of multiferroic $\mathrm{YFeo}_{3}$ nanopowders and their optical and magnetic properties. Materials 2017, 10, 626. [CrossRef]

20. Shannon, R.D. Revised effective ionic radii and systematic studies of interatomic distances in halides and chalcogenides. Acta Crystallogr. A 1976, 32, 751-767. [CrossRef]

21. Chakrabarti, K.; Das, K.; Sarkar, B.; Ghosh, S.; De, S.K.; Sinha, G.; Lahtinen, J. Enhanced magnetic and dielectric properties of $\mathrm{Eu}$ and $\mathrm{Co}$ co-doped $\mathrm{BiFeO}_{3}$ nanoparticles. Appl. Phys. Lett. 2012, 101, 759. [CrossRef]

22. Yang, L.P.; Zhang, A.M.; Dai, Y.; Wu, X.S. The effect of Dy-Fe co-doping on the structural and magnetic properties of h-YMnO ${ }_{3}$. J. Mater. Sci. Mater. Electron. 2017, 28, 8872-8877. [CrossRef]

23. Wu, L.; Yu, J.C.; Zhang, L.; Wang, X.; Li, S. Selective self-propagating combustion synthesis of hexagonal and orthorhombic nanocrystalline yttrium iron oxide. J. Solid State Chem. 2004, 177, 3666-3674. [CrossRef] 
24. Ma, Y.; Chen, X.M.; Lin, Y.Q. Relaxorlike dielectric behavior and weak ferromagnetism in $\mathrm{YFeO}_{3}$ ceramics. J. Appl. Phys. 2008, 103, 124111. [CrossRef]

25. Moriya, T. New mechanism of anisotropic superexchange interaction. Phys. Rev. Lett. 1960, 4, $228-230$. [CrossRef]

26. Dzyaloshinsky, I. A thermodynamic theory of weak ferromagnetism of antiferromagnetics. J. Phys. Chem. Solids 1958, 4, 241-255. [CrossRef]

27. Arlt, G.; Hennings, D.; With, G.D. Dielectric properties of fine-grained barium titanate ceramics. J. Appl. Phys. 1985, 58, 1619-1625. [CrossRef]

28. Zhang, Y.; Yang, J.; Xu, J.; Gao, Q.; Hong, Z. Controllable synthesis of hexagonal and orthorhombic $\mathrm{YFeO}_{3}$ and their visible-light photocatalytic activities. Mater. Lett. 2012, 81,1-4. [CrossRef]

29. Mocherla, P.S.V.; Karthik, C.; Ubic, R.; Rao, M.S.R.; Sudakar, C. Tunable bandgap in $\mathrm{BiFeO}_{3}$ nanoparticles: The role of microstrain and oxygen defects. Appl. Phys. Lett. 2013, 103, 2463-2485. [CrossRef]

30. Zhang, Q.; Zhu, X.; Xu, Y.; Gao, H.; Xiao, Y.; Liang, D.; Zhu, J.; Zhu, J.; Xiao, D. Effect of La $^{3+}$ substitution on the phase transitions, microstructure and electrical properties of $\mathrm{Bi}_{1-\mathrm{x}} \mathrm{La}_{\mathrm{x}} \mathrm{FeO}_{3}$ ceramics. J. Alloys Compd. 2013, 546, 57-62. [CrossRef]

31. Shen, T.; Hu, C.; Yang, W.L.; Liu, H.C.; Wei, X.L. Theoretical investigation of magnetic, electronic and optical properties of orthorhombic $\mathrm{YFeO}_{3}$ : A first-principle study. Mater. Sci. Semicond. Process. 2015, 34, 114-120. [CrossRef]

32. Liu, J.; He, F.; Chen, L.; Qin, X.; Zhao, N.; Huang, Y.; Peng, Y. Novel hexagonal-YFeO $\mathrm{O}_{3} / \alpha-\mathrm{Fe}_{2} \mathrm{O}_{3}$ heterojunction composite nanowires with enhanced visible light photocatalytic activity. Mater. Lett. 2016, 165, 263-266. [CrossRef]

(C) 2019 by the authors. Licensee MDPI, Basel, Switzerland. This article is an open access article distributed under the terms and conditions of the Creative Commons Attribution (CC BY) license (http://creativecommons.org/licenses/by/4.0/). 